DOI 10.37882/2500-3682.2021.04.14

\title{
ПЕРСПЕКТИВЫ ИЗУЧЕНИЯ АЛЬТРУИЗМА: КРАТКИЙ ОБЗОР ЗАРУБЕЖНЫХ ИССЛЕДОВАНИЙ
}

\section{PERSPECTIVES FOR THE STUDY OF ALTRUISM: A BRIEF OVERVIEW OF FOREIGN RESEARCHES}

E. Leonova

Summary: The article provides a brief overview of foreign theories of altruism according to the model of helping and altruism by J.F. Dovidio, L.A. Penner. The article presents researches that prove the connection between empathy and altruism, in which empathy acts as an affective component and a dispositional personality trait. Promising researches of altruism include the study of narcissistic personality traits, altruism born of suffering, and the impact of altruism on happiness, health, and wellbeing.

Keywords: altruism, altruistic motivation, helping behavior.
И сторически изучение терминов «просоциальное поведение» (prosocial behavior) и «альтруизм» (altruism) началось в социологических теориях второй половины XIX века, где просоциальное поведение использовалось как антоним антисоциального поведения [3]. Для объяснения просоциального поведения социолог О. Конт в 1875 г. ввел понятие «альтруизм», противопоставляя его эгоизму. Русско-американский социолог П.А. Сорокин в 1950 г. одним из первых исследователей провел систематическое эмпирическое изучение альтруистических личностей, используя метод экстремальных групп. В дальнейшем этот метод использовался для анализа альтруистических личностей и героических поступков во время Второй мировой войны.

В зарубежной социальной психологии изучение «помогающего поведения» (helping behavior) и альтруизма началось с анализа случая Китти Дженовезе в 1964 г. Психологами J.M. Darley, B. Latane в 1968 г. была опубликована первая эмпирическая статья с моделированием данного случая [8]. В дальнейшем авторы разработали модель принятия решения о помощи в чрезвычайных ситуациях и описали «эффект свидетеля» (bystander effect).

Во второй половине XX в. в социальной психологии изучались детерминанты альтруизма при помощи лабораторных экспериментов, выявляя социальные и ситуационные факторы помощи. В это же время в социологии анализировались социальные движения, рассматривающие вместе просоциальное поведение, помогающее поведение и альтруизм.
Леонова Екатерина Николаевна

Аспирант, Удмуртский государственный университет (2. Ижевск); Преподаватель, Ижевская государственная медицинская академия, leonova@psyman.pro

Аннотация: В статье проводится краткий обзор зарубежных теорий альтруизма согласно модели помощи и альтруизма J.F. Dovidio, L.A. Penner. Представлены исследования, доказывающие связь эмпатии с альтруизмом, в которых эмпатия выступает как аффективный компонент и диспозиционная черта личности. К перспективным исследованиям альтруизма относится его изучение с учетом нарциссических черт личности, альтруизм, порожденный страданием, и влияние альтруизма на счастье, здоровье и благополучие.

Ключевые слова: альтруизм, альтруистическая мотивация, помогающее поведение.

Целью статьи является краткий обзор и систематизация зарубежных теорий альтруизма согласно модели помощи и альтруизма J.F. Dovidio, L.A. Penner. Обзор зарубежных теорий дополнен результатами современных эмпирических исследований альтруизма.

При соотношении терминов просоциальное поведение, помогающее поведение (помощь) и альтруизм, просоциальное поведение является наиболее широким понятием. Просоциальное поведение «включает в себя целый ряд видов поведения, направленных на благо других, таких как помощь, участие, сотрудничество, утешение и пожертвования на благотворительность» [9, р. 162]. Помогающее поведение относится к «просоциальным действиям в диадических ситуациях, в которых один человек нуждается, а другой оказывает необходимую помощь для устранения потребности другого» [24, р. 140]. Исходя из целей помощи, альтруизм выступает как «мотивационное состояние с конечной целью повышение благосостояния другого» [1, р. 16], когда при эгоизме результат помощи идет на благо самого человека.

Модель помощи и альтруизма предложена J.F. Dovidio, L.A. Penner [9], которая в виде пирамиды иерархически связывает теории и исследования в области помогающего поведения и альтруизма. Авторы выделили пять уровней: первые уровни описывают базовые теории просоциального поведения, уровни постепенно сужаются до пятого уровня - формы помощи. В своем исследовании за основу классификации теорий альтруизма мы взяли данную модель и дополнили ее результатами современ- 
ных исследований.

Первый уровень модели помощи и альтруизма содержит теории, связанные с эволючионными процессами и включенной приспособленностью (C. Darwin, W.D. Hamilton, N.L. Segal и др.) Одним из компонентов включенной приспособленности является родственный отбор, когда спасение жизни родственников, даже ценой собственной жизни, увеличивает частоту встречаемости генов в поколениях. Под реципрокным (взаимным) альтруизмом R.L. Trivers понимает генетическую предрасположенность к взаимопомощи, увеличивающую включенную приспособленность и вероятность передачи генов родственникам [33]. Как отмечает H.A. Simon, альтруистические индивиды вносят вклад в формирование общества, поэтому с большей вероятностью выживут, передав генетические предрасположенности потомкам [27].

В экспериментальном исследовании при сравнении монозиготных и дизиготных пар близнецов J.P. Rushton, D.W. Fulker, M.C. Neal, D.K. Nias, H.J. Eysenck выявили генетическую наследуемость альтруизма [27]. В их исследовании альтруизм возрастал в возрасте от 19 до 60 лет, при чем в каждом возрасте женщины имели более высокие баллы по альтруизму, чем мужчины. Объяснение полученных результатов заключалось в гонадном гормоне тестостероне, который уменьшается с возрастом, тем самым снижает агрессивность и повышает эмпатию.

S. Stewart-Williams обнаружил отличия в стоимости помощи и взаимного обмена между родственниками и друзьями [32]. В его исследовании подтвердилось, что с возрастанием стоимости помощи родственники получали больше помощи, чем друзья. Большая степень родства была связана с более высоким уровнем помощи. Уровень взаимного обмена был выше среди друзей, чем родственников, однако среди родственников тоже был высокий уровень взаимного обмена.

Кроме экспериментальных исследований с выбором помощи в конкретных ситуациях продолжается поиск причин альтруизма на генетическом уровне. А. Knafo, S. Israel приводят доказательства наследуемости просоциального поведения на генном уровне [18]. В их исследованиях обсуждаются взаимодействия между генетическими и средовыми факторами просоциального поведения, выявлена более высокая наследуемость альтруизма в семьях с дополнительными братьями и сестрами.

C.D. Batson подчеркивает важность отличий эволюционного альтруизма от психологического [11]. Эволюционный альтруизм характерен эволюционным психологам и биологам, которые рассматривают альтруизм как снижение собственной приспособленности ради повышения приспособленности другого, принесение себя в жертву ради другой особи. «Психологический альтруизм - это мотивация с конечной целью повышения благосостояния другого... Эволюционный альтруизм не является ни необходимым, ни достаточным условием для возникновения психологического альтруизма» [11, p. 17].

Второй уровень модели помощи и альтруизма включает теории, объясняющие оказание помощи и проявления альтруизма через когнитивные и аффективные прочессы (C.D. Batson, J.F. Dovidio, N. Eisenberg, J.E. Grusec, E. Staub и др.), обоснованные через процессы обучения, возбуждения и аффекта. E. Staub описывает становление форм помощи через оперантное обучение, обусловленное аффективным положительным и негативным подкреплением [31]. J.E. Grusec, M. Davidov, L. Lundell подчеркивают важность социального обучения для усвоения моделей поведения, которые имеют долгосрочное влияние на социальную норму помощи [15].

J.E. Grusec, J.J. Goodnow изучали влияние родителей на формирование у детей интернальных тенденций помощи [16]. Авторы предположили, что первый этап интернализации ценностей помощи включает точное восприятие детьми сообщения агента социализации (обычно родителя), второй этап - принятие этого сообщения. Первый этап связан с четким, частым и последовательным выражением ценности помощи в соответствии с познавательными способностями ребенка. Второй этап интернализации связан с тремя переменными. Первая переменная - это аргументы в пользу просоциального поведения, когда требования родителей кажутся разумными и вмешательство ребенка соответствует его темпераменту и настроению. Наказания детей за отказ от помощи в меньшей степени способствует интернализации ценностей помощи. Вторая переменная связана с мотивацией принять сообщение от родителя, когда возникает эмпатическое возбуждение и желание угодить родителю при минимальных угрозах автономии ребенка. Третья переменная - ребенок должен чувствовать, что руководствуется нормой, выработанной им самим.

При рассмотрении аффективных процессов подкрепления помощи J.E. Grusec, M. Davidov, L. Lundell выделяют различия между эмпатией и сопереживанием [15]. Эмпатия (empathy) в ходе социального обучения выступает как сопереживание и правильнее использовать термин сочувствие (sympathy). Как отмечают авторы, сочувствие является аффективной реакцией на чужое страдание и выражается в чувстве печали или беспокойстве за другого.

C.D. Batson вводит необходимость отличия эмпатии и сочувствия от личных страданий [1]. Эмпатия и сочувствие ориентированы на других, когда личные страдания являются самонаправленными реакциями и вклю- 
чают негативные эмоции (тревогу, беспокойство). За счет эмпатии и сочувствия помощь оказывается с целью улучшения состояния другого, когда при личных страданиях - для облегчения собственного дискомфорта, возможно даже отсутствие просоциального поведения (например, уход из ситуации).

Исследования N. Eisenberg, N.D. Eggum показали, что личные страдания вызывают более высокий уровень физиологического возбуждения, чем сочувствие [12]. Люди с развитой саморегуляцией сочувствуют вне зависимости от силы эмоциональной реактивности, способны поддерживать оптимальный уровень эмоционального возбуждения и не доводят его до высокого (личных страданий).

Большинство авторов признают роль эмпатического возбуждения как аффективно-мотивационного компонента просоциального поведения, но у них нет единства понимания природы эмоций и того, что именно заставляет людей помогать другим. Так в модели «возбуждение: затраты-вознаграждение» (arousal: cost-reward model) эмпатическое возбуждение несет мотивационный компонент для оказания помощи, но форма помощи будет зависеть от анализа затрат и вознаграждений [10]. Помощь другим - это способ снизить возникшее возбуждение, но вознаграждения от помощи должны превосходить личные затраты.

На третьем уровне модели помощи и альтруизма представлены теории, учитывающие ситуационные, социальные и личностные факторы (J.M. Darley, B. Latane, L. Berkowitz, G.H. Hofstede, L.A. Penner и др.) J.M. Darley, B. Latane одними из первых разработали модель принятия решения о вмешательстве стороннего наблюдателя [20]. Модель включает пять этапов: заметить, что что-то не так; определить это как ситуацию, которая требует какого-то вмешательства; решить, брать ли на себя личную ответственность; решить, какую помощь оказать; осуществить выбранные действия. Отрицательное решение на любом этапе может привести к отказу в помощи. В последствии эта модель использовалась для оценки многих ситуаций, от вождения автомобиля в нетрезвом виде до решения пожертвовать почку.

Рискованный альтруизм (risky altruism), как анализ героических поступков, «проявляется в уникальных сочетаниях пространства и времени; ... его трудно предвидеть» $[11$, p. 7]. S.W. Becker, A.H. Eagly выявили гендерные особенности в проявлении рискованного альтруизма в ситуациях с риском для собственной жизни: при попытке спасения других было больше мужчин, когда женщинам более свойственно быть среди спасателей холокоста, доноров почек, добровольцев корпуса мира и врачей [4]. Объяснение различий связано с усвоением гендерных норм и существующими в обществе культур- ными стереотипами.

В процессе социализации формируются ценности, оказывающие влияние на проявление альтруизма в обществе. S.W. Smith, M.K. Lapinski, M.J. Bresnahan, S.L. Smith подчеркивают важность роли культуры в формировании личности и поведения [28]. Авторами предполагается, что в индивидуалистических культурах альтруистическое поведение исходит из личного решения и выбора, когда в коллективистских культурах альтруистическое поведение - вопрос роли и обязательства.

Нормативные теории помощи связаны с ожиданиями от других, основанных на социальном обучении или поведении с социально приемлемой реакцией. L. Berkowitz указывает, что согласно норме социальной ответственности, люди должны помогать тем, кто от них зависит, даже если от этого не будет ощутимой выгоды [5]. При этом автор вводит исключение, что люди менее обязаны придерживать норме социальной ответственности, если взаимозависимые отношения нежелательны или угрожают личной свободе и выбору.

Однако, как указывают J.F. Dovidio, L.A. Penner, социальные нормы действуют как общий стандарт поведения, при этом для конкретной ситуации важен учет личных норм и стандартов поведения [9]. Если в ситуации помощи предлагаются деньги или есть давление из вне (внешние стимулы), то возможно менее альтруистичное поведение.

J.A. Everett, L. Caviola, G. Kahane, J. Savulescu, N.S. Faber в исследованиях показали, что участники жертвовали большую сумму денег на благотворительность, когда это был вариант по умолчанию (default effects) [14]. В ceрии экспериментов, где можно было оставить выбор по умолчанию - сделать пожертвование, или убрать выбор по умолчанию - оставить себе бонусные деньги, 81\% респондентов выбирали пожертвование. Пожертвование как выбор по умолчанию воспринимался как социально нормативный вариант.

Просоциальные диспозиционные переменные - это «устойчивые личностные качества, которые во времени и ситуациях связаны с последовательностью проявления помогающих или альтруистических действий» [9, р. 178]. К демографическим переменным относят возраст, этническую принадлежность, социально-экономический статус, религию и пол. Предполагается, что люди при достижении материальных целей, начинают обращаться к целям, дающих больше смысла в жизни, поэтому люди становятся более склонны к благотворительности.

N. Eisenberg в исследованиях выявила, что женщины более склонны к помощи, чем мужчины, потому что женщины сильнее испытывают физиологическое возбуждение 
и интерпретируют его как эмпатическую реакцию [12]. В исследованиях автора доказано, что просоциальные диспозиции, связанные с эмпатией, проявляются в позднем детстве и относительно стабильны во взрослой жизни [13].

L.A. Penner, B.A. Fritzsche, J.P. Craiger, T.R. Freifeld ввели более широкое понятие - просоциальная ориентация личности (prosocial personality orientation) [22]. В их исследованиях показано, что с просоциальным поведением и просоциальной личностью связана эмпатия, ориентированная на других (other-oriented empathy). Такие люди обладают сильным чувством социальной ответственности, сопереживают и чувствуют эмоциональную привязанность к нуждающимся, понимают проблемы, с которыми сталкивается жертва, и имеют повышенное чувство морального долга быть полезными. Другой характеристикой просоциальной ориентации личности является услужливость (helpfulness), связанная с поведенческим компонентом, когда люди в прошлом были чем-то полезны, и они верят, что могут быть чем-то полезны в будущем.

Четвертый уровень модели помощи и альтруизма учитывает чели и мотивы поведения (C.D. Batson, R.B. Cialdini и др.), выделяя эгоистические и альтруистические мотивы помощи. C.D. Batson под альтруизмом понимает «мотивационное состояние с конечной целью увеличения благосостояния другого. Альтруизм противопоставляется эгоизму, мотивационному состоянию с конечной целью повышения собственного благосостояния» [1, р. 16]. Автор подчеркивает важность выделения целей помощи и не отрицает, что сама помощь является снятием возникшего возбуждения. Оказание помощи может помочь избежать наказания или, наоборот, будет способствовать вознаграждению. Однако, при альтруистической мотивации это будет являться непреднамеренными последствиями.

R.B. Cialdini c соавторами предлагали модель облегчения негативного состояния (negative-state relief model), в которой предполагается, что люди помогают, чтобы чувствовать себя лучше [6; 7]. Помощь может служить вторичным подкреплением, усвоенным в ходе социализации, которое облегчает негативные состояния. В процессе помощи у человека снижаются негативные эмоциональные состояния (чувство вины, печаль), что является эгоистической мотивацией.

В исследованиях C.D. Batson с коллегами подтвердили, что у эмпатически возбужденных людей манипуляции с повышением настроения могут служить эффективным источником облегчения негативного состояния [2]. Однако, манипуляции настроением никак не влияли на высокоэмпатичных респондентов, которые демонстрировали большую помощь, чем респонденты с низкой эмпатией. Эти результаты исследований подтверждают гипотезу о связи эмпатии с альтруизмом.

S.W. Smith с соавторами предлагают рассматривать альтруистическое поведение как «поведение, направленное на благо других, выходящего за рамки простой общительности или обязанностей, связанных с ролью (например, семьей или работой). Все альтруистические поступки, по определению, должны быть законными» $[29$, p. 711$]$.

Таким образом, возможны альтруистические действия, выходящие за рамки предписанных социальных норм, ролей и правил поведения, в которых личные выгоды возможны как следствия от альтруистических мотивов помощи.

Пятый уровень помощи и альтруизма связан непосредственно с формой оказания помощи. J.F. Dovidio, L.A. Penner выделяют прямую форму помощи, связанную с личным участием в помощи, и косвенную, включающую опосредованные действия, например, вызов полиции [9]. Формы помощи можно еще разделить на краткосрочные и долгосрочные, персональные и анонимные. Бездействие в определенных ситуациях необходимо классифицировать как отказ от помощи, когда существуют внутренние или внешние барьеры для принятия решения о помощи.

За счет включенной приспособленности эволюционные подходы помощи и альтруизма объясняют оказание помощи родственникам и близким, что также может выражаться на генетической предрасположенности к просоциальному поведению. Активация такой предрасположенности происходит за счет когнитивных и аффективных процессов, среди которых важное место отводится аффективной эмпатии и условиям социализации, связанными с подкреплением помогающего поведения и усвоением моделей поведения в обществе. В зависимости от ситуационных, социальных факторов и личностных диспозиций происходит принятие решения о помощи, детерминированных альтруистической или эгоистической мотивацией. Помогающее поведение показывает результаты действий, когда альтруизм является мотивационным компонентом помощи.

Современные исследования строятся на основе многоуровневого понимания помогающего поведения и альтруизма. Как отмечает J.A. Piliavin, изучение помощи и альтруизма необходимо начинать с микро-генетико-физиологического уровня, через мезо-межличностный уровень и заканчивая макроорганизационным уровнем [23].

В серии исследований W.G. Graziano, M.M. Habashi, B.E. Sheese изучалась связь между просоциальной мотивацией, эмпатией и помогающим поведением, учитывались личностные детерминанты испытуемых и использо- 
валось манипулирование ситуационными переменными [37]. Исследование показало, что у людей с низкой просоциальной мотивацией, когда затраты на помощь высоки, попытки вызвать эмпатию ситуативно подрывали просоциальное поведение. Такие респонденты, вместо того чтобы быть эмоционально невосприимчивыми к жертвам, в ситуациях высоких затрат на помощь воспринимали страдание жертв более эгоцентрично и оказывали меньше помощи, потому им не хватало навыков смещения фокуса эмоциональных реакций (эмпатического аффекта и просоциальной мотивации) с себя на жертву и ее потребности.

Феномен альтруизма активно изучается в рамках позитивной психологии. A.S. Irani под позитивным альтруизмом (positive altruism) понимает «улучшение благосостояния, как дающего, так и получающего помощь» [17, р. 41]. Эмпатия может способствовать альтруистическим действиям, но также она может создать предвзятость в принятии решений и привести к эмоциональному заражению, как следствие, развитию выгорания и истощения. Автором предлагаются практики любящей доброты (loving-kindness meditation), способствующие развитию сопереживания и заботы, и одновременной защите от эмоционального заражения, что влияет на улучшение здоровья и благополучия.

S.G. Post в обзоре исследований связи альтруизма со счастьем и здоровьем показывает существование сильной корреляции между благополучием, счастьем, здоровьем и долголетием людей, которые эмоционально и поведенчески сострадательны, но при условии, если люди они не перегружены задачами помощи [25].

В основном просоциальное поведение изучается на основе прошлого положительного опыта, но введено понятие альтруизма, порожденного страданием (altruism born of suffering). Это современный мало изученный феномен, связанный с тем, как отмечает E. Staub, что люди после негативного жизненного опыта или травматических событий имеют склонность к антисоциальному поведению, но при трансформации своих переживаний такие люди демонстрируют помощь и желание заботиться о других [31]. J.R. Vollhardt предлагает введение трех переменных в модель альтруизма, порожденного страданием: категории травматического события и просоциального поведения, мотивационные процессы и волевые переменные [34].

В экспериментальных исследованиях J.R. Vollhardt, E. Staub показали, что люди, пострадавшие от неблагоприятных жизненных событий, с большей вероятностью окажут помощь нуждающимся внешним группам, чем те, кто не страдал [35]. Авторы обнаружили, что просоциальное отношение к жертвам цунами было самым высоким среди тех, кто пострадал подобным образом (стихийных бедствий). Эффект опосредовали эмпатия и снижение внутригрупповых предубеждений, но не личные страдания. Для трансформации негативного жизненного опыта в альтруизм, порожденным страданием, предлагается рассмотрение жертв как потенциальных помощников общества.

Если рассматривать доминирующую теорию о связи эмпатии и альтруизма, то каким образом проявляется альтруизм у психопатических личностей? B.A. White отмечает, что основной чертой психопатии является отсутствие эмпатии [36]. В его исследовании обнаружена связь первичной психопатии с публичным просоциальным поведением и обратная связь с анонимным и альтруистическим просоциальным поведением, эти связи были опосредованы отсутствием эмпатии.

J.A. Palmer, S. Tackett, изучая связь темной триады (макиавеллизм, нарциссизм и субклиническая психопатия) с просоциальным поведением, выявили у испытуемых с выраженными особенностями темной триады низкий уровень эмпатии [21]. При этом такие личности проявляют просоциальное поведение, детерминированное личной пользой от помощи. В их исследовании нарциссизм положительно коррелировал с реципрокным альтруизмом и самоотчетными данными альтруистических поступков, отрицательно с аффективной эмпатией.

Как отмечают S. Konrath, Y. Tian, нарциссические личности могут заниматься просоциальной деятельностью, если она является легкой, быстрой и одноразовой, предполагающей четкие выгоды и вознаграждения для себя [19]. Авторами выявлено, что люди с нарциссическими чертами личности завышают данные при самооценке альтруистических поступков. В связи с этим становится актуальным изучение помогающего поведения и альтруизма с учетом нарциссических черт личности.

Подходы к изучению альтруизма начались с анализа поведения в чрезвычайных ситуациях и вышли на уровень изучения альтруизма как многоуровневого феномена. Доминирующей теорией существования альтруизма является связь эмпатии с альтруизмом, которая выступает как аффективный компонент (сочувствие) и как диспозиционная черта личности. В виду использования самоотчетных методов измерения альтруизма, в исследованиях необходимо учитывать нарциссические черты личности. Современные исследования альтруизма проводятся в рамках позитивной психологии, где альтруистические действия связаны с повышением счастья, здоровья и благополучия. Возможно использование альтруистических действий для включения и адаптации людей в общество после неблагоприятных жизненных событий. Проведенный обзор зарубежных исследований открывает новые возможности для изучения альтруизма в отечественной психологии. 


\section{ЛИТЕРАТУРА}

1. Batson C.D. Empathy-induced altruistic motivation / Mikulincer M., Shaver P.R. (Eds.). Prosocial motives, emotions, and behavior. Washington, DC: American Psychological Association, 2010. P. 15-35.

2. Batson C.D., Batson J.G., Griffitt C.A., Barrientos S., Brandt J.R., Sprengelmeyer P., Bayly M.J. Negative-state relief and the empathy-altruism hypothesis // Journal of Personality and Social Psychology. 1989. Vol. 56. P. 922-933.

3. Batson C.D., Powell A.A. Altruism and prosocial behavior / Millon T., Lerner M.J. (Eds.). Handbook of Psychology: Personality and Social Psychology, Vol. 5, Hoboken, NJ, US: John Wiley and Sons Inc, 2003. P. 463-84.

4. Becker S.W., Eagly A.H. The heroism of men and women // American Psychologist. 2004. Vol. 59. P. 163-178.

5. Berkowitz L. Reactance and the unwillingness to help others // Psychological Bulletin. 1973. Vol. 79. P. 310-317.

6. Cialdini R.B., Baumann D.J., Kenrick D.T. Insights from sadness: a three-step model of the development of altruism as hedonism // Development Review. 1981. Vol. 1. P. 207-223

7. Cialdini R.B., Darby B.L., Vincent J.E. Transgression and altruism: a case for hedonism // Journal of Experimental Social Psychology. 1973. Vol. 9. P. $502-516$.

8. Darley J.M., Latane B. Bystander intervention in emergencies: diffusion of responsibility // Journal of Personality and Social Psychology. 1968. Vol. 8. P. 377-383.

9. Dovidio J.F., Penner L.A. Helping and altruism / Fletcher G., Clark M.S. (Eds.). International Handbook of Social Psychology: Interpersonal Processes. Oxford: Blackwell Sci., 2001. P. 162-195.

10. Dovidio J.F., Piliavin J.A., Gaertner S.L., Schroeder D.A., Clark R.D. III. The Arousal: CostReward Model and the process of intervention: a review of the evidence / Clark M.S. Prosocial behavior. Newbury Park, CA: Sage, 1991. P. 86-118.

11. Draguns, J.D. Altruism in its personal, social, and cultural contexts: an introduction / Vakock D.A (Ed.). Altruism in Cross-Cultural Perspective. New York: Springer, 2013. P. 1-16.

12. Eisenberg N., Eggum, N.D. Empathic responding: sympathy and personal distress / Decety J., Ickes W. (Eds.). The Social Neuroscience of Empathy. Cambridge, MA: MIT Press, 2009. P. 71-83.

13. Eisenberg N., Guthrie I.K., Cumberland A., Murphy B.C., Shepard S.A., et al. Prosocial development in early adulthood: a longitudinal study // Journal of Personality and Social Psychology. 2002. Vol. 82. P. 993-1006.

14. Everett J.A., Caviola L., Kahane G., Savulescu J., Faber N.S. Doing good by doing nothing? The role of social norms in explaining default effects in altruistic contexts // European Journal of Social Psychology. 2015. Vol. 45(2). P. 230-241.

15. Grusec J.E., Davidov M., Lundell L. Prosocial and helping behavior / Smith P.K., Hart C.H. (Eds.). Childhood Social Development: Blackwell Handbooks of Developmental Psychology. Malden, MA: Blackwell Sci., 2002. P. 457-74.

16. Grusec J.E., Goodnow J.J. Impact of parental discipline methods on the child's internalization of values: a reconceptualization of current points of view // Developmental Psychology. 1994. Vol. 30. P. 4-19.

17. Irani A. Positive altruism: helping that benefits both the recipient and giver // Master of Applied Positive Psychology (MAPP) Capstone Projects, 152.2018.

18. Knafo A., Israel S. Genetic and environmental influences on prosocial behavior / Mikulincer M., Shaver P. (Eds.). Prosocial motives, emotions, and behavior. Washington, DC: American Psychological Association, 2010. P. 149-169.

19. Konrath S., Tian Y. Narcissism and prosocial behavior / Hermann A.D., Brunell A.B., Foster J.D. (Eds.). The handbook of trait narcissism: Key advances, research methods, and controversies. New York, NY: Springer, 2018. P. 309-316.

20. Latané B., Darley J.M. The unresponsive bystander: why doesn't he help? New York, NY: Appleton-Century Crofts, 1970.

21. Palmer J.A., Tackett S. An examination of the dark triad constructs with regard to prosocial behavior // Acta Psychopathologica. 2018. Vol. 4. P. 1-3.

22. Penner L.A., Fritzsche B.A., Craiger J.P., Freifeld T.R. Measuring the prosocial personality / Butcher J., Spielberger C.D. (Eds.). Advances in Personality Assessment. Hillsdale, NJ: LEA, 1995. Vol. 10. P. 147-163.

23. Piliavin J.A. Altruism and helping: the evolution of a field: the 2008 Cooley-Mead presentation // Social Psychology Quarterly. 2009. Vol. 72. P. $209-225$.

24. Poepsel D.L., Schroeder D.A. Helping and prosocial behavior / Biswas-Diener R., Diener E. (Eds.). HKU PSYC2020, Fundamentals of Social Psychology. Noba Textbook Series: Psychology. Champaign, IL: DEF Publishers, 2018. P. 141-158.

25. Post S.G. Altruism, happiness, and health: it's good to be good // International Journal of Behavioral Medicine. 2005. Vol. 12, N. 2. P. 66-77.

26. Rushton J.P., Fulker D.W., Neal M.C., Nias D.K., Eysenck H.J. Altruism and aggression: The heritability of individual differences // Journal of Personality and Social Psychology. 1986. Vol. 50. P. 1192-1198.

27. Simon H.A. A mechanism for social selection and successful altruism // Science. 1990. Vol. 250. P. 1665-1668.

28. Smith S.W., Lapinski M.K., Bresnahan M.J., Smith S.L. Conceptual aspects of altruism in cross-cultural contexts / Vakoch D.A. (Ed.). Altruism in cross-cultural perspective. New York, NY: Springer, 2013. P. 17-29.

29. Smith S.W., Smith S.L., Pieper K.M., Yoo J.H., Ferris A.L., Downs E., Bowden B. Altruism on American television: examining the amount of, and context surrounding acts of helping and sharing // Journal of Communication. 2006. Vol. 56 (4). P. 707-727.

30. Staub E. Emergency helping, genocidal violence, and the evolution of responsibility and altruism in children / Davidson R.J., Harrington A. (Eds.). Western Scientists and Tibetan Buddhists Examine Human Nature. London: Oxford Univ. Press, 2002. P. 165-181.

31. Staub E. The roots of goodness: the fulfillment of basic human needs and the development of caring, helping and nonaggression, inclusive caring, moral courage, 
active bystandership, and altruism born of suffering / Carlo G., Edwards C. (Eds.). Moral motivation through the life span. Lincoln: University of Nebraska Press, 2005. P. 33-72.

32. Stewart-Williams S. Altruism among kin vs. nonkin: effects of cost of help and reciprocal exchange // Evolution and Human Behavior. 2007. Vol. 28. P. 193-198.

33. Trivers R.L. The evolution of reciprocal altruism // Quarterly Review of Biology. 1971. Vol. 46. P. 35-37.

34. Vollhardt J.R. Altruism born of suffering and prosocial behavior following adverse life events: a review and conceptualization // Social Justice Research. 2009. Vol. 22. P. 53-97.

35. Vollhardt J.R., Staub E. Inclusive altruism born of suffering: The effects of past suffering on prosocial behavior toward outgroups // American Journal of Orthopsychiatry. 2011. Vol. 81. P. 307-305.

36. White B.A. Who cares when nobody is watching? Psychopathic traits and empathy in prosocial behaviors // Personality and Individual Differences. 2014 . Vol. 56. P. 116-121.

37. Graziano W.G., Habashi M.M, Sheese B.E., Tobin R.M. Agreeableness, empathy, and helping: a person x situation perspective // Journal of Personality and Social Psychology. 2007. Vol. 93, N. 4. P. 583-599.

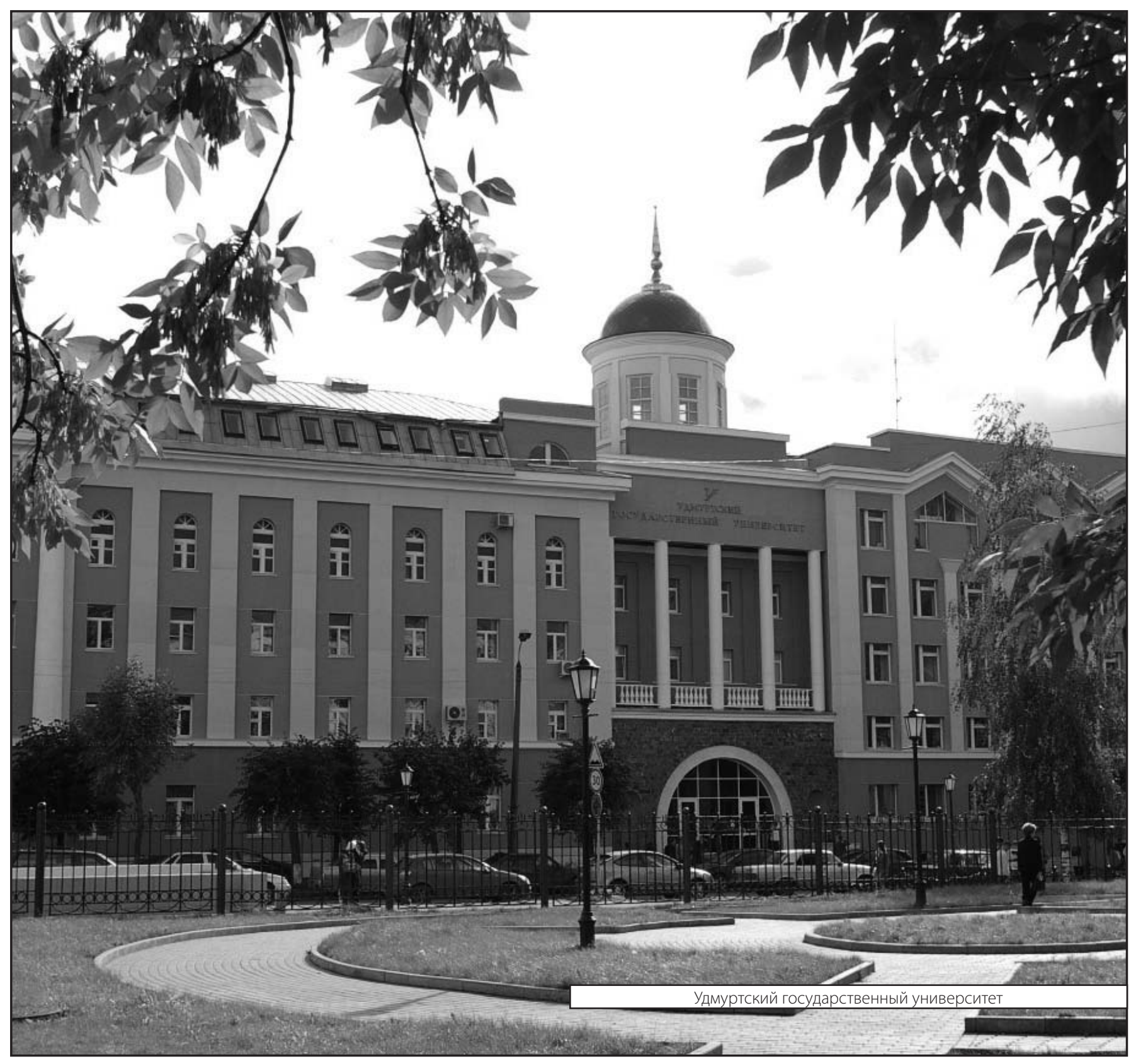

